\title{
Mesangial Cell Autoantigens in Immunoglobulin A Nephropathy and Henoch-Schönlein Purpura
}

\author{
Donal J. O'Donoghue, Angela Darvill, and Francis W. Ballardie \\ Department of Medicine, University of Manchester, \\ Manchester Royal Infirmary, Manchester M13 9WL, United Kingdom
}

\begin{abstract}
The autoantigen(s) that we have previously described in human glomeruli, recognized in IgA nephropathy, has (have) been identified as mesangial cell in origin. Cultured mesangial cells expressed 48- and 55-kD components binding IgG isotype autoantibodies (IgG-MESCA) present in sera of patients with both IgA nephropathy and Henoch-Schönlein purpura (HSP). IgGMESCA were not detected in sera of normals, or patients with other autoimmune-mediated glomerulonephritides: anti-glomerular basement membrane disease, Wegener's granulomatosis, or in IgM-mesangial proliferative disease. Binding specificity was proven by $\mathrm{F}\left(\mathbf{a b}^{\prime}\right)_{2}$ studies in enzyme-linked immunosorbent assay (ELISA) and Western blotting, and there was no significant affinity of IgA or IgM immunoglobulins. Fluorescein isothiocyanate-conjugated IgG from ELISA-positive sera localized to the mesangium and peripheral capillary loops of glomeruli, supporting the belief that the antigen is expressed in normal human renal tissue. However, only about one third of mesangial cells in culture showed affinity for IgG from ELISApositive sera, suggesting variable expression of the antigen(s) in vitro. The only autoantigen(s) present in glomeruli, and extractable from whole normal glomeruli by the techniques employed, localized on the mesangial cell.

In both IgA nephropathy and HSP, autoimmunity was intermittently present, with fluctuating levels of IgG-MESCA detectable in sera. There were positive correlations with the degree of glomerular injury assessed by erythrocyturia and proteinuria in IgA nephropathy, but significance was reached with only the degree of hematuria in HSP. These findings suggest a contributing role in the pathogenesis of the mesangial proliferative lesions and demonstrate autoimmunity common to both IgA nephropathy and HSP. (J. Clin. Invest. 1991. 88:15221530.) Key words: autoimmunity $\bullet \operatorname{IgA}$ nephropathy $\bullet$ mesangial cell antigens
\end{abstract}

\section{Introduction}

Mesangial deposition of immune reactants with hypercellularity and matrix expansion is characteristic of the glomerular

Address reprint requests and correspondence to Dr. Ballardie, Manchester Royal Infirmary, Oxford Road, Manchester M13 9WL, United Kingdom.

Received for publication 4 December 1990 and in revised form 27 March 1991.

1. Abbreviations used in this paper: HSN, Henoch-Schönlein nephritis; HSP, Henoch-Schönlein purpura; IgAN, IgA nephropathy; MESCA, anti-mesangial cell antibody.

J. Clin. Invest.

(C) The American Society for Clinical Investigation, Inc. $0021-9738 / 91 / 11 / 1522 / 09 \quad \$ 2.00$

Volume 88, November 1991, 1522-1530 lesion of IgA nephropathy (IgAN) (1). Berger and Hinglais (2) and Druet and his co-workers (3) described IgA-IgG mesangial nephropathy, with initial reports emphasizing co-deposition of both immunoglobulin isotypes. Persistent mesangial IgA deposition as the dominant or codominant immunoglobulin, with IgG deposition, remains the diagnostic criterion (4) in 14$100 \%$ (5-7), variable on repeat biopsy (8). In contrast, IgM deposition is generally found in sclerotic glomeruli (9), suggesting deposition may be a consequence of different mechanisms such as nonspecific trapping described in idiopathic focal segmental glomerulosclerosis (10).

The histopathological features of Henoch-Schönlein nephritis (HSN) are strikingly similar to those of IgAN and the patterns of immune deposits within the mesangium show many similarities (11). Henoch-Schönlein purpura (HSP) is distinguished by its characteristic accompanying rash due to a leukocytoclastic dermal vasculitis (12). However, deposition of IgA within the dermal vasculature is also found in IgAN (13). Furthermore, both are associated with synpharyngitic hematuria, transition between syndromes has been described (14), and familial cases can occur (15), implying shared pathogenic factors in these IgA-related nephropathies.

In both diseases, abnormal IgA regulation, impaired reticuloendothelial cell system phagocytic function, and elevated circulating, IgA-containing immune complexes have been found by a range of assays (16). Consequently, it has been assumed that IgAN and HSN are mediated by glomerular deposition of IgA immune complexes. Despite an extensive search, no exogenous antigen, such as those derived from bacteria, viruses, or food has been identified consistently or reproducibly in sera of glomeruli, nor do levels or forms of IgA-containing circulating immune complexes correlate with either the clinical features of nephritis or prognosis (17). Indeed, the nonphlogistic nature of IgA (18), occurrence of mesangial deposits of $\operatorname{IgA}$ alone in celiac disease (19) without evidence of nephritis or, in hepatobiliary disease, with only minor urinary abnormality, suggests that other mechanisms may be involved in glomerular injury in IgA-related nephropathies.

The difficulty in reproducing the disease characteristics in experimental models with IgA deposition alone has focused attention on the role of exogenous antigens, different classes of glomerular immune deposits (20), and recently, cytokines. Related but distinct antigens that elicit the same degree of $\operatorname{IgA}$ deposits in experimental animals can be associated with marked differences in glomerular reactions owing to antigenmediated complement activation (21). In humans, there is evidence for polyclonal B cell activation (16), hypersensitivity to environmental antigens, and antigenic heterogeneity of infecting organisms (22). Complement deposition appears to be a prerequisite for nephritogenesis in experimental IgAN, and in these systems the importance of IgG complexes capable of fixing complement in an oral immunization model of IgAN is apparent $(23,24)$. Clinicopathological observations also sup- 
port the concept that co-deposition of complement-fixing IgG may be critical for nephritogenesis. In HSN circulating IgGcontaining immune complexes are restricted to those with glomerular involvement (25), and the presence of mesangial IgG deposits may be associated with more severe renal manifestations and glomerular scarring in IgAN (26).

Autoimmunity to glomerular structures has been difficult to establish in IgA-related nephropathies, since patients also have species present in sera that bind to environmental and food-derived antigens. Other forms of autoimmunity have been recognized, as IgA rheumatoid factor activity, in patients with IgAN (27). Enhanced immunoglobulin binding to nuclear proteins (28), endothelial cells (29), and bovine laminin (30) has also been reported but these have not been identified unequivocally as autoantigens, present in the human glomerulus, and may represent binding to either diet-derived xenogeneic antigens, or to endothelial cells that have known heterogeneity between various sites in the vasculature: the binding of immunoglobulins to endothelial cells from umbilical veins may thus be to determinants absent in the renal vasculature. The immunochemical nature of these interactions has also not been clarified, and they may be related to nonspecific IgA binding as was recently shown between IgA-fibronectin immune complexes and type IV collagen (31). We have described autoantibodies of IgG isotype with specific affinity shown on $\mathrm{F}\left(\mathrm{ab}^{\prime}\right)_{2}$ studies, recognizing glomerular components distinct from the Goodpasture antigen in $\operatorname{IgAN}(32,33)$ and $\mathrm{HSN}(34)$. Autoantibody detection was intermittent and associated with clinical evidence of nephritis suggesting an immunopathogenic role. Affinity-purified, fluorescein isothiocyanate (FITC)-conjugated IgG bound to peripheral capillary loop regions of normal human renal tissue, suggesting localization of the autoantigen to these areas.

The present study in IgA-related nephropathies was undertaken to detect any antigens capable of functioning as autoantigens, present in the human glomerulus, and to define their cellular localization. The results show that the only autoantigen was present on the mesangial cell and was of molecular mass $48-55 \mathrm{kD}$, binding IgG antibodies with specificity proven by $\mathrm{F}\left(\mathrm{ab}^{\prime}\right)_{2}$ studies, in the sera of patients with IgAN and HSP with active nephritis.

\section{Methods}

\section{Patients and controls}

The study population consisted of 40 patients with primary IgAN (28 male, 12 female) with an age range of 19-56 yr (median 34) and 20 patients with HSN (12 male, 8 female) with an age range of 4-27 yr (median $14 \mathrm{yr}$ ). Sera from 40 blood donors were used as controls. Sera from 20 patients with other forms of glomerulonephritis were used as patient controls. Eight of these had IgM mesangial proliferative glomerulonephritis (five male, three female; median age $37 \mathrm{yr}$ ), eight membranous nephropathy (six male, two female; median age 44 yr), all chosen at random, and two each with known seropositivity in relevant autoimmune assays (anti-glomerular basement membrane, anti-neutrophil antibody), anti-glomerular basement membrane disease or Wegener's granulomatosis (two male, two female; median age $54 \mathrm{yr}$ ). Sera were separated from clotted blood and stored at $-70^{\circ} \mathrm{C}$.

Longitudinal study and clinical correlates. 16 patients (10 IgAN and $6 \mathrm{HSP}$ ) were studied longitudinally for 3 mo to 4 yr during different phases of their disease. Clinical features and routine laboratory assessments (serum creatinine, 24-h urinary protein excretion, and urinary erythrocyte count) were correlated with anti-mesangial cell antibody (MESCA) levels (q.v.) in serum obtained stimulanteously.

\section{Laboratory methods}

Mesangial cell antigen preparation. Whole human glomeruli were isolated and mesangial cells were cultured as previously described (35). Glomeruli were separated by standard sieving procedures from normal human kidney, from organs not used for transplantation or from partial nephrectomy specimens, not involving any form of renal tumor, with $<\mathbf{4}$ h of warm ischemia in all cases. These were suspended at a density of $1,000 / \mathrm{ml}$ in RPMI- 1640 supplemented with $20 \%$ heat-inactivated fetal calf serum, $125 \mathrm{U} / \mathrm{ml}$ of penicillin, $125 \mu \mathrm{g} / \mathrm{ml}$ of streptomycin, and $2 \mathrm{mmol} \mathrm{L-glutamine}$ and cultured in plastic flasks coated with fibronectin. Epithelial cell outgrowth was evident between days 10 and 21 and the primary glomerular cultures were passaged between three and five times to obtain a pure mesangial preparation. This was characterized by spindle morphology and hillock formation: immunofluorescence characteristics showed the presence of actin $F$ identified by phalloidin and desmin staining (Zymed Labs. Inc., S. San Francisco, CA) and the absence of factor VIII-related antigen (36) and PHM5 staining (Serotec Ltd., Oxford, UK) for endothelial or epithelial cells, respectively. The medium was removed, washed, and replaced with serum-free RPMI-1640 1 d before harvesting the cells for extraction. The cells were stripped from the flasks using $0.5 \mathrm{mmol}$ EDTA with trypsin $(0.5 \mathrm{~g} / 100 \mathrm{ml})$ and gentle agitation, washed three times in serum-free phosphate-buffered saline (PBS), and resuspended in complete Hanks' medium at a concentration of $50 \times 10^{6} / \mathrm{ml}$. Disruption was achieved by 101 -min high-power ultrasound pulses at $4^{\circ} \mathrm{C}$ and was confirmed by microscopy, followed by centrifugation at $50,000 \mathrm{rpm}$ for $10 \mathrm{~min}$, to remove cellular debris. The water-soluble portion was used as ligand.

Enzyme-linked immunosorbent assay (ELISA) for anti-mesangial cell antibodies (IgG-MESCA). $100 \mu \mathrm{l}$ of a 1 in 50 dilution of mesangial cell ligand in $0.1 \mathrm{M}$ carbonate-bicarbonate buffer, $\mathrm{pH} 9.6$, was used to coat 96-well plastic microtiter plates (Dynatek, Billingshurst, Sussex, UK), overnight at $4^{\circ} \mathrm{C}$. The plates were washed thrice with a solution of $0.05 \%$ Tween 20 in PBS, pH 7.4 (PBS/Tween), between each incubation, and the plastic binding sites were saturated by incubation with $1 \%$ Tween 20 in PBS for $1 \mathrm{~h}$ at room temperature. Patient and control sera were diluted 1 in 40 in PBS/Tween (optimal signal: background optical density [OD] ratio was achieved at this dilution: data not shown), and $100-\mu \mathrm{l}$ aliquots were incubated in coated and uncoated wells in duplicate for $2 \mathrm{~h}$ at $37^{\circ} \mathrm{C}$. Bound IgG antibody was detected with a murine monoclonal antibody directed against human IgG heavy chain (GG7, ICN immunobiologicals diluted 1 in 1,000 in PBS/Tween). Assays were performed in duplicate, and standards in triplicate, for IgA and IgM affinity. Sera were also diluted from 1 in 20 maximum concentration, and examined with affinity-purified goat anti-human IgA or IgM (Sigma Chemical Co., St. Louis, MO) diluted 1 in 500 in PBS/Tween, incubated for $4 \mathrm{~h}$ at room temperature followed by peroxidase-conjugated rabbit anti-mouse immunoglobulin, or anti-goat immunoglobulin at 1 in 500 in PBS/Tween for $2 \mathrm{~h}$ at room temperature. The assay was developed using amino-bis-ethyl-benzthiazoline sulphonic acid at $1 \mathrm{mM}$ in $0.1 \mathrm{M}$ citrate phosphate buffer at $\mathrm{pH} 5$ with $0.1 \mathrm{mM}$ hydrogen peroxide for $1 \mathrm{~h}$ at room temperature before reading spectrophotometrically at $420 \mathrm{~nm}$ using a multiscan plate reader. Each plate contained an equal number of samples from IgA-related nephropathy patients and controls. Sequential samples were tested in the same plate. Dilutions of a pool of known positive reference sera were incubated in each plate to maximum OD 1.5. Variations in antigenic content between different preparations of mesangial cell antigen were thus standardized. The upper limit of normal was taken as the mean plus 2 SD of the normal control group. Results are expressed as ELISA optical density under standardized conditions.

Preparation of whole glomerular antigen. Whole glomeruli from more than one source of human tissue were separated and disrupted by prolonged sonication at $4^{\circ} \mathrm{C}$ and ultracentrifuged, and the supernatant was dialyzed against PBS and antibody binding detected by the standard form of previously described ELISA (33).

$F\left(a b^{\prime}\right)_{2}$ studies. The IgG fraction of eight ELISA-positive sera (four IgAN, four HSP) and six normal controls was separated by ammonium 
sulfate precipitation, and $\mathrm{F}\left(\mathrm{ab}^{\prime}\right)_{2}$ fragments were cleaved by papain digestion (37) and separated from the Fc fragments using a Sepharose column. The $F\left(a b^{\prime}\right)_{2}$ preparations were concentrated to the starting volume using a concentrator (Amicon Corp., Beverly, MA) and were shown to be free of intact IgG and $\mathrm{Fc}$ fragments by ELISA with mouse monoclonal anti-human IgG (GG7) detected by peroxidase-conjugated rabbit anti-mouse immunoglobulin and developed as described. The $\mathrm{F}\left(\mathrm{ab}^{\prime}\right)_{2}$ fragments were used at a dilution of 1 in 500 in PBS/Tween to detect specific mesangial antigen binding using the standard ELISA modified by substituting a mouse monoclonal antibody specific for regions of $F\left(a^{\prime}\right)_{2}$-GG6 for the GG7.

Immunoblotting. $10 \%$ sodium dodecyl sulfate (SDS) polyacrylamide gels were prepared and electrophoresed by standard methods using available molecular mass standards. After SDS-PAGE of $25 \mu \mathrm{l}$ of the mesangial cell ligand, or alternatively, whole glomeruli (33) under denaturing and reducing conditions, transfer to nitrocellulose was made and the nitrocellulose strips were blocked with $1 \%$ Tween 20 in PBS for $1 \mathrm{~h}$ before overnight incubation with patient or control sera at 1 in $20 \mathrm{PBS} /$ Tween at $4^{\circ} \mathrm{C}$. Molecular mass standards for the range 26$200 \mathrm{kD}$ (Pharmacia, Uppsala, Sweden) were used. IgG binding was detected using GG7 at 1 in 500 dilution in PBS/Tween for $4 \mathrm{~h}$ at room temperature followed by washing and incubation with peroxidase-conjugated rabbit anti-mouse immunoglobulin 1 in 500 in PBS/Tween for $2 \mathrm{~h}$. The nitrocellulose strips were developed with 3,3-diaminobenzidine tetrahydrochloride dihydrate $1 \mathrm{mg} / \mathrm{ml}$ in PBS with $\mathrm{H}_{2} \mathrm{O}_{2} 1 \mu \mathrm{l} / 10$ $\mathrm{ml}$, and the reaction was stopped by extensive washing with distilled water and drying.

Fast protein liquid chromatography (FPLC)-ELISA profiles. The mesangial cell extract was dialyzed against $20 \mathrm{mM}$ Tris-HCl $\mathrm{pH} 7.7$ and fractionated on a mono- $\mathrm{Q}$ column eluted with a $0-1 \mathrm{M}$ sodium chloride gradient in Tris- $\mathrm{HCl} 20 \mathrm{mmol}$ using a FPLC system (Pharmacia). Fractions were monitored for protein content by optical density at $280 \mathrm{~nm}$ and collected in 96-well microtiter plates incubated overnight at $4^{\circ} \mathrm{C}$ and assayed by ELISA with known positive sera as described above.

Direct immunofluorescence studies. IgG from ELISA-positive patients and normal controls was separated by ammonium sulfate precipitation and conjugated with biotin by the method of Guesdan et al. (38). Biotinylated IgG at $10 \mu \mathrm{g} / \mathrm{ml}$ was applied to human mesangial cells in culture and normal human kidney sections, which had been preincubated for $30 \mathrm{~min}$ with $1 \%$ gelatin, and incubated at $4^{\circ} \mathrm{C}$ for $30 \mathrm{~min}$, washed with PBS, and developed by incubating with streptavidin-biotin complex conjugated to FITC (Pharmacia) and examined under fluorescence microscopy.

\section{Statistical analysis}

All results are expressed as mean \pm standard deviation. ANOVA and multiple inference statistics were used for comparison of anti-mesangial antigen antibody levels between groups and sequential data; incidences of positive results were compared by $\chi^{2}$ tests. The relationship between antibody levels and clinical parameters was examined by Kendall's rank correlation.

\section{Results}

IgG-MESCA: anti-mesangial cell antibodies. The ELISA assay showed dependence on the preparation and source of the human mesangial cells: only preparations with standard positive sera, with normal control OD ratios $>5$, were used for the standardized assay. Dilution curves of mesangial cell antigen showed no significant variation in the OD of serum binding between 1 in 20 and 1 in 150 dilutions (data not shown). A dilution of 1 in 50, mid-plateau, was chosen for the standardized assay.

Sera from 27 out of 40 patients with IgAN and 14 out of 20 with HSN displayed increased IgG binding to the mesangial
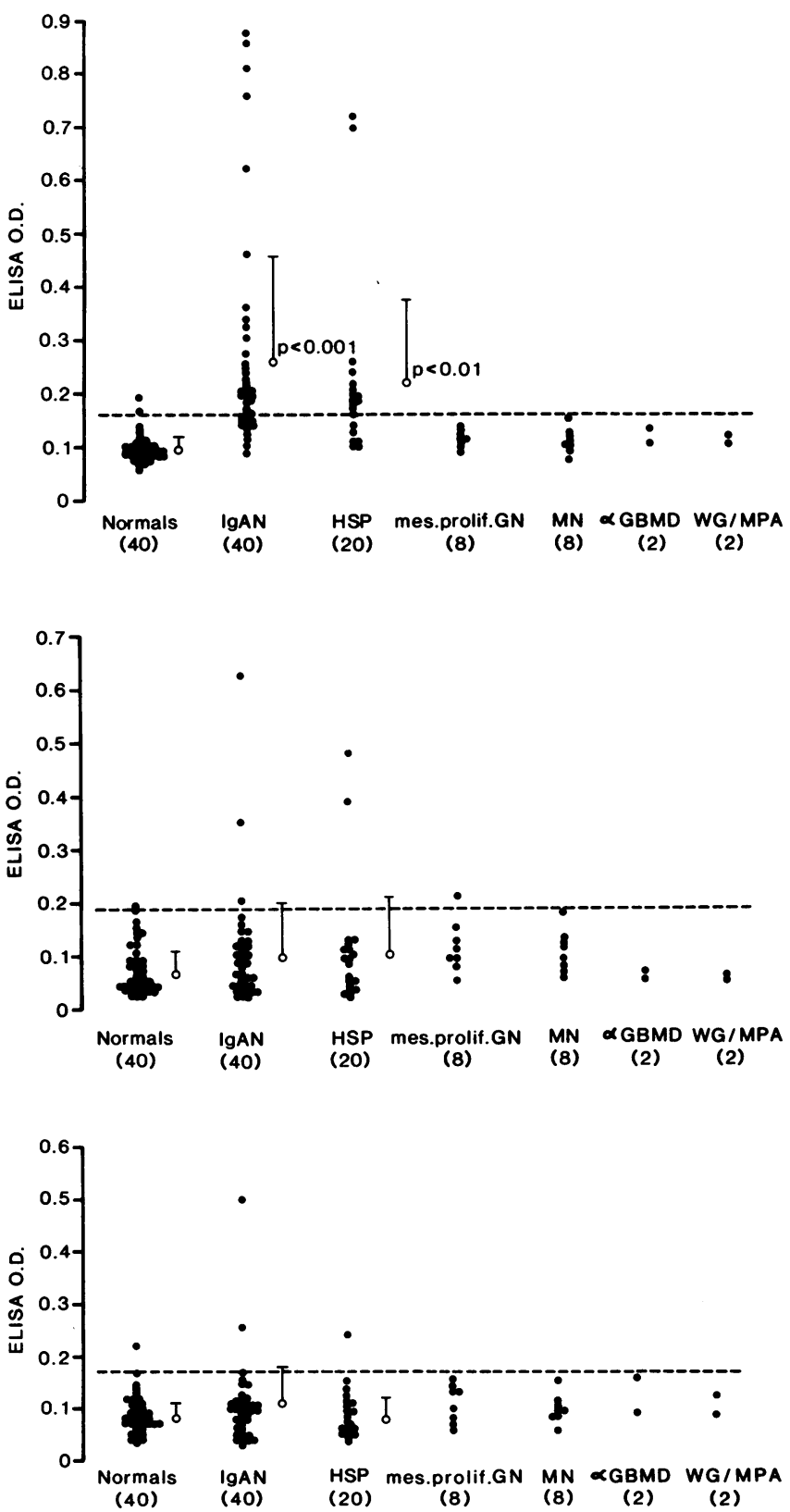

Figure 1. (Top) Distribution of IgG isotype antimesangial cell activity in IgAN patients, HSP patients with or without active nephritis or other glomerulopathies (see text), and controls. Dashed horizontal line represents upper limit of normal IgG binding. $0=$ mean; vertical bar shows $1 \mathrm{SD}$. (Middle) IgA isotype antimesangial cell activity. (Bottom) IgM isotype antimesangial cell activity.

cell ligand in ELISA compared to the normal control group ( $F$ $=9.12, P<0.001$, Fig. 1, top). Three of the IgG-positive sera also showed weak affinity for IgA and IgM, greater than controls, which was apparent at dilutions up to 1 in 200 , but neither IgA-related nephropathy group had statistically signifcantly raised binding of these isotypes to the mesangial cell ligand (for IgA disease: $F=0.36, P=0.7$, Fig. 1 , middle; $F$ $=0.49, P=0.6$, Fig. 1 , bottom). In sera examined, total IgG remained within the normal range in all specimens, compared 


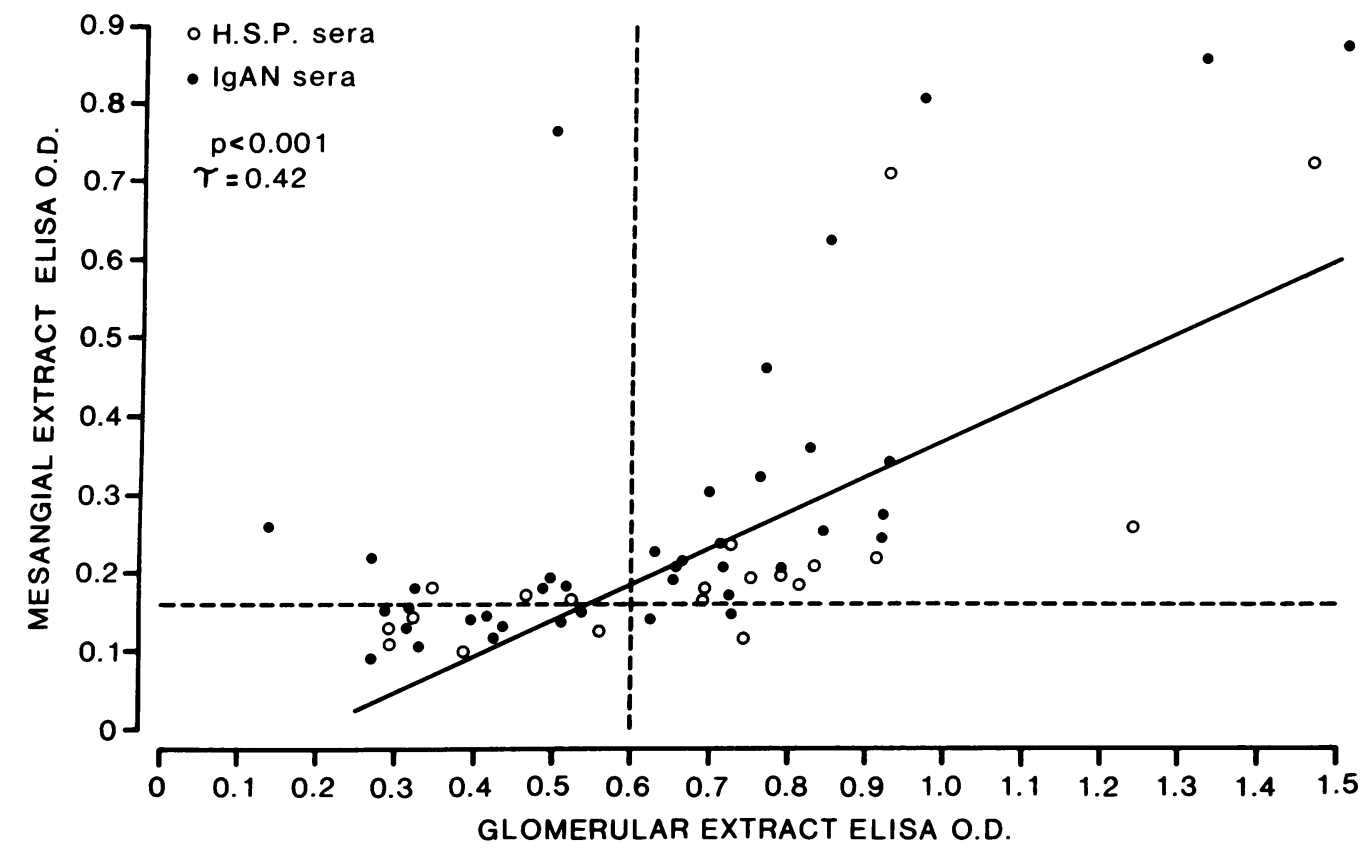

Figure 2. Correlation between the IgG isotype antimesangial cell activity and IgG antiglomerular activity by ELISA in IgAN and HSP patients. Dashed horizontal and vertical lines represent upper limit of IgG binding in each assay. with a 10 -fold range in IgG-MESCA; there was no correlation between total IgG and IgG-MESCA. Of the 20 patients with non-IgA-related glomerulonephritis, none was positive in ELISA for any of the isotypes tested in comparison to the normal control group.

$\mathrm{F}\left(\mathrm{ab}^{\prime}\right)_{2}$ fragments isolated from ELISA-positive sera, randomly selected from both IgA disease and HSP, bound to mesangial antigens in ELISA when compared with control sera $(P$ $<0.02, n=4-6$ patients per group).

Comparison between mesangial cell and glomerular ligands. Comparison between the ELISA signals measured after coating with either mesangial cell or whole glomerular extracted ligand was performed with sera. There was a good correlation ( $\tau_{k}=0.42, P<0.001$, Fig. 2$)$. The mesangial ligand resulted in greater sensitivity than the whole glomerular preparation $\left(42 / 60\right.$ positive vs. $31 / 60$ positive, $\left.\chi^{2} P<0.05\right)$ and the modification of ELISA conditions resulted in lower nonspecific background binding (OD of controls with mesangial cell extract $0.09 \pm 0.03$ vs. $0.4 \pm 0.1$ with whole glomerular extract, $P$ $<0.001$ ).

The apparent molecular mass of the antigens, recognized by IgG-MESCA was determined by Western blot analysis of the reduced and denatured human mesangial cell and whole glomerular extracts prepared as for ELISA. Protein bands of $M_{\mathrm{r}}$ 48,000 and $55,000 \mathrm{kD}$ were specifically stained by IgG from ELISA-positive sera, from patients with IgAN or HSP using both ligands, but not by the normal control sera (Fig. 3). The sensitivity of blotting for detection of autoantibody in sera was apparently higher than ELISA in that a number of sera showed low-intensity IgG binding on Western blotting to the antigen(s), but were negative by ELISA, likely a reflection of small amounts of autoantibody in sera, the binding of which was not above the background ELISA signal. Identical appearances were observed when $F\left(a b^{\prime}\right)_{2}$ fragments were applied, and the blot was developed with monoclonal antibody GG6.

FPLC-ELISA profiles. FPLC-ELISA analysis showed consistently detected peaks in fractions 50,70 , and 190 in six patients studied, from the mono- $Q$ column eluted by $1 \mathrm{M}$ sodium chloride. However, there was variation between individuals with immunoreactivity to peaks in fractions $130-140$ in two patients, with either IgAN or HSN. A typical ELISA profile is shown in Fig. 4.

Localization of antigen. Immunofluorescence studies showed binding of IgG from ELISA-positive sera to approximately one third of all mesangial cells in culture in a uniform speckled membrane-associated pattern (Fig. 5) but no binding of ELISA-negative sera.

In thin sections of normal human kidney incubated with biotin-conjugated IgG from ELISA-positive sera from six patients, followed by incubation with streptavidin-biotin-FITC, the label was observed mainly in the peripheral mesangium and paramesangial regions (Fig. 6).

Clinical disease associations. In the cross-sectional study urinary erythrocyte excretion and proteinuria but not serum creatinine correlated with the level of IgG autoantibody (Table I). During the prospective follow-up study the episodes of nephritis were associated with high levels of circulating IgG

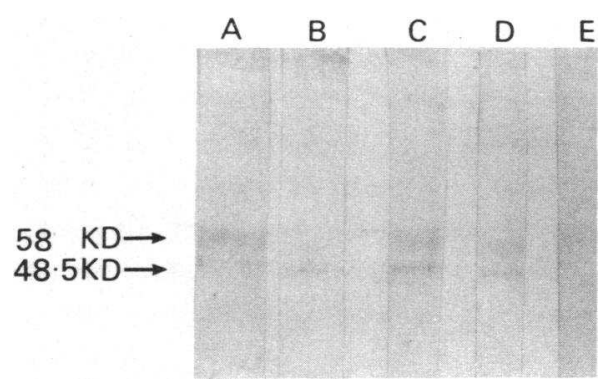

Figure 3. Western blot of mesangial cell extract (lanes $A, C$, and $E$ ) and crude glomerular extract (lanes $B$ and $D$ ). Lanes $A$ and $B$ are incubated with IgAN patient serum; lanes $C$ and $D$ were incubated with HSP serum, and lane $E$ was incubated with normal human serum. Consistent bands at 55 and $48 \mathrm{kD}$ are identified by IgG from sera of both IgAN and HSP patients but not normal serum. F(ab') fragments of IgG binding was similarly demonstrated (not shown). 


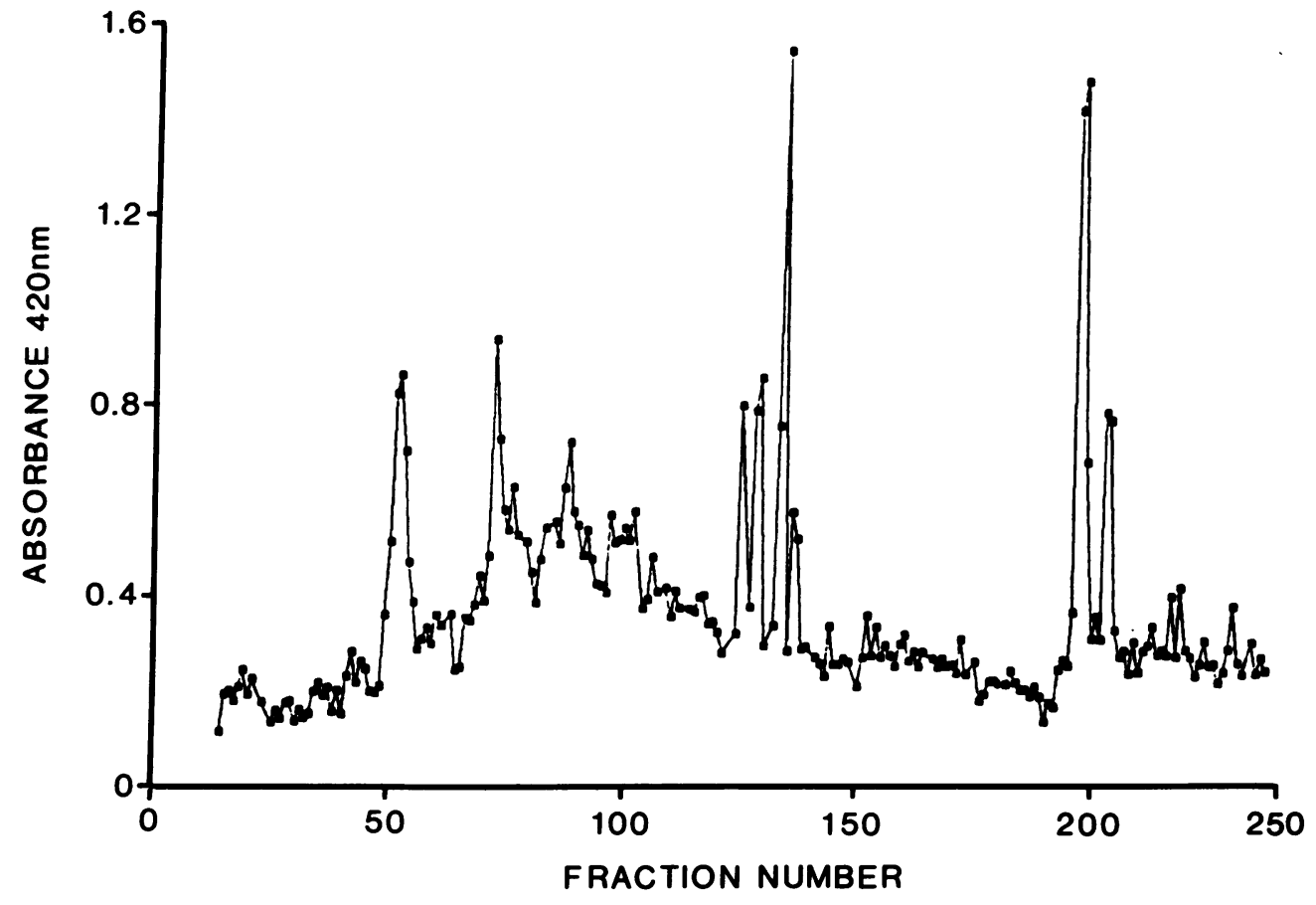

Figure 4. IgG autoantibody affinity from FPLC-ELISA analysis to fractions of mesangial extract in a HSP patient. autoantibodies compared to during periods of partial or complete clinical remission (Fig. 7). In individual patients there was a close temporal relationship between autoantibody levels and the clinical markers of nephritis as illustrated in Fig. 8. However, the autoantibody was not detected in four other episodes of active HSP involving other organ systems, but without renal involvement (data not shown).

\section{Discussion}

This study demonstrates novel IgG autoantibody binding specifically to glomerular antigen(s) present on the mesangial cell and found only in IgAN nephropathy and HSP. Restriction of serum immunoglobulin isotypes and autoantibody binding glomerular structures suggests true autoimmunity in IgA-re-

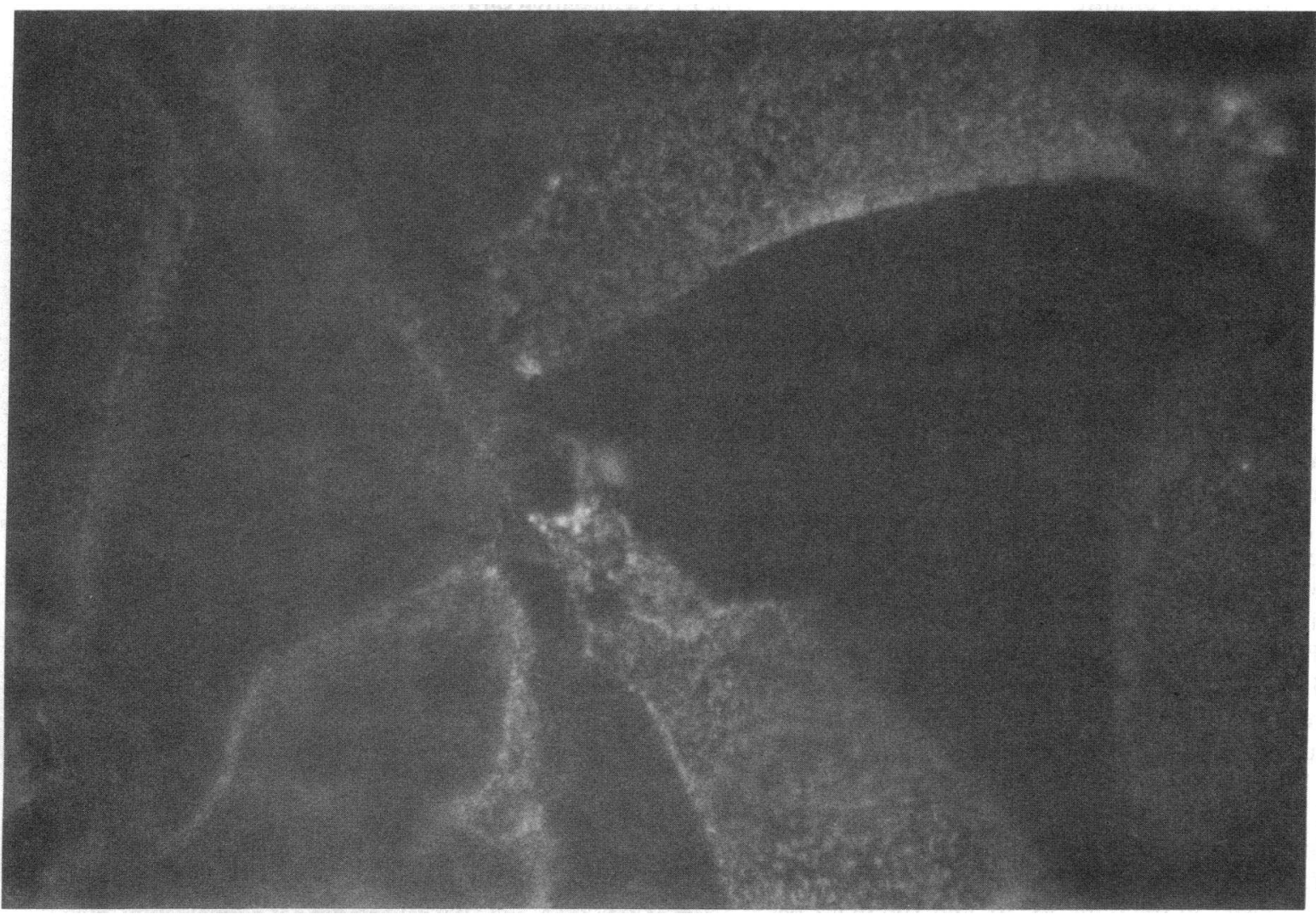

Figure 5. IgG from an IgAN patient bound to mesangial cell in culture in a speckled membrane pattern by indirect immunofluorescence. 


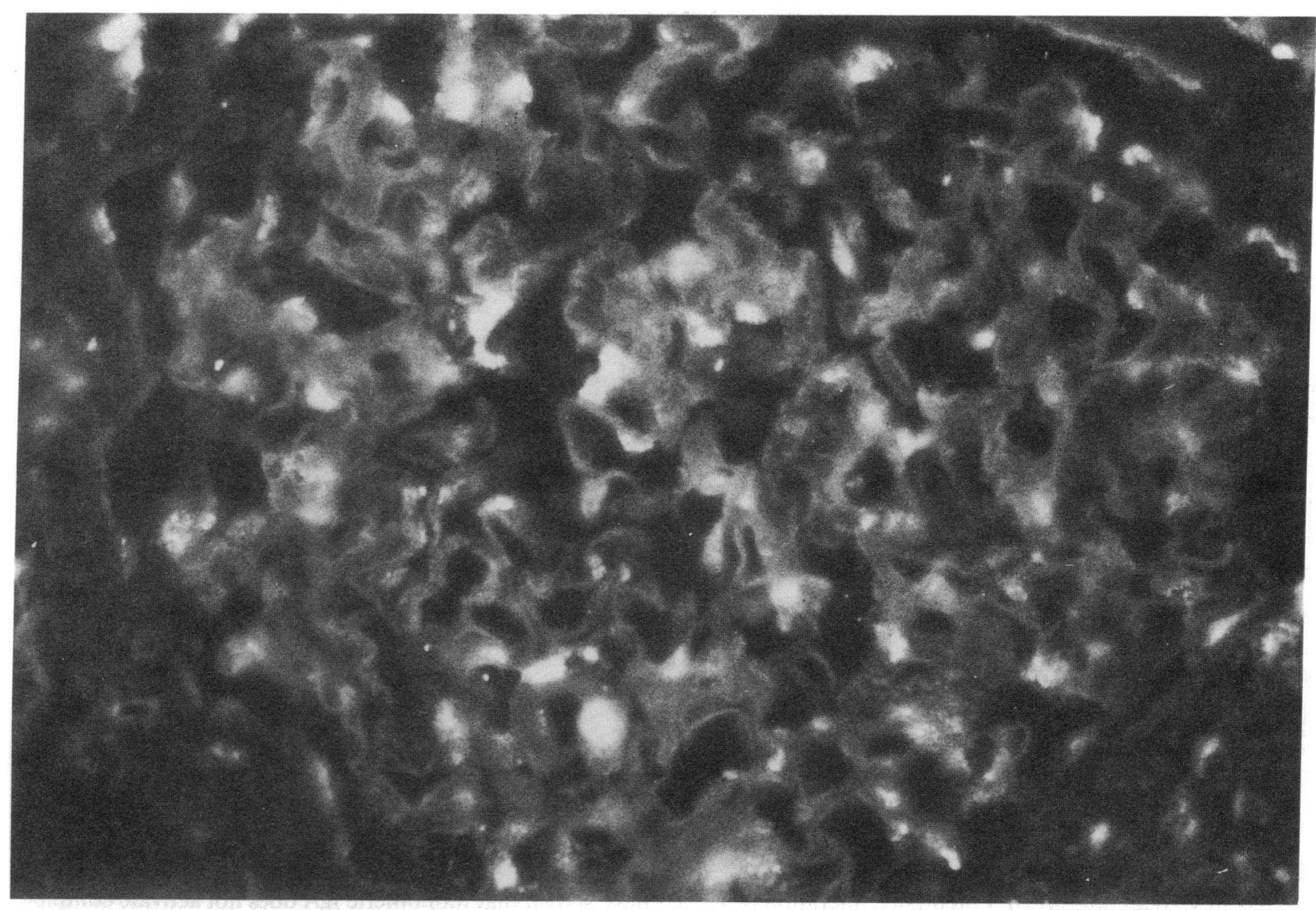

Figure 6. Localization of IgG binding to the peripheral mesangium and paramesangium regions by direct immunofluorescence of FITC-conjugated IgG from an IgAN patient.

lated nephropathies may be limited, in contrast to the wider range of species in sera with affinity for foreign antigens. The absence of IgG-MESCA in non-IgA-related forms of mesangial proliferative glomerulonephritis and other nephropathies defines a common autoimmune component in IgAN nephropathy and HSP and suggests that the pathogenesis of IgA-related nephropathies should be regarded as distinct within the spectrum of mesangial glomerulonephritis.

The existence of IgG autoantibodies to mesangial cell components, in the absence of an IgA response in serum up to 1 in 20 concentration, detectable using only autoantigenic (reference 33 and this study), not potentially xenoantigenic, ligands, in these conditions is intriguing in the light of the wide spectrum of IgA system abnormalities (4) and the diagnostic hallmark of mesangial IgA deposition in these nephritides (1). How-

Table I. Correlation between IgG-MESCA and Erythrocyturia, Proteinuria, and Serum Creatinine

\begin{tabular}{lrrr}
\hline & Erythrocyturia & Proteinuria & $\begin{array}{c}\text { Serum } \\
\text { creatinine }\end{array}$ \\
\hline IgAN patients $(n=40)$ & & & \\
$\quad R_{s}$ & 0.726 & 0.38 & 0.11 \\
$P$ & $<0.001$ & $<0.01$ & $>0.05$ \\
HSP patients $(n=20)$ & & & \\
$\quad R_{s}$ & 0.89 & 0.2 & 0.17 \\
$P$ & $<0.01$ & $>0.05$ & $>0.05$ \\
\hline
\end{tabular}

ever, co-deposition of IgG within the mesangium is an associated feature in a large proportion of cases (5) but its potential pathogenic role has been neglected (4). The observation that IgG deposition in serial biopsy studies is intermittent $(1,8)$ suggests its true prevalence is underestimated in routine clinical practice.

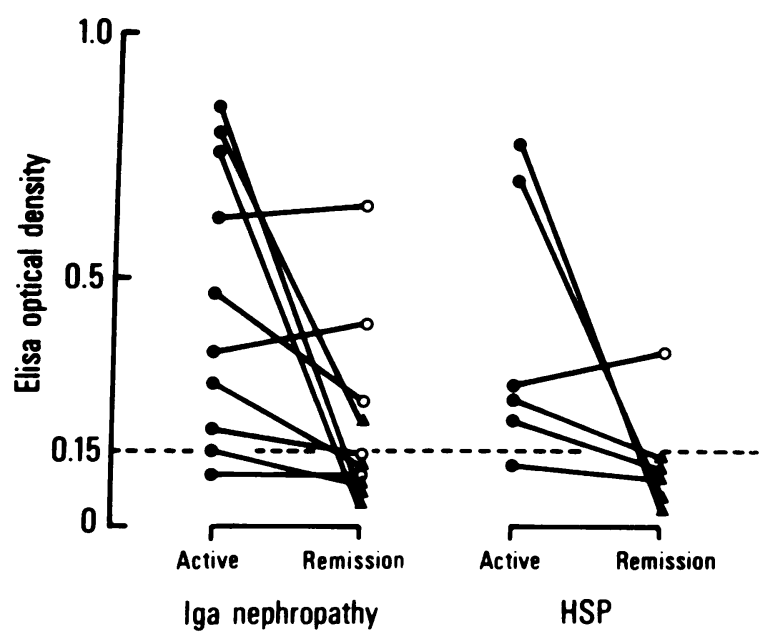

Figure 7. Anti-mesangial cell IgG autoantibody levels during episodes of active nephritis and remission in $\operatorname{IgAN}(n=10)$ and $\operatorname{HSP}(n=6)$. Dashed horizontal line represents the upper limit of IgG binding in normal controls. 

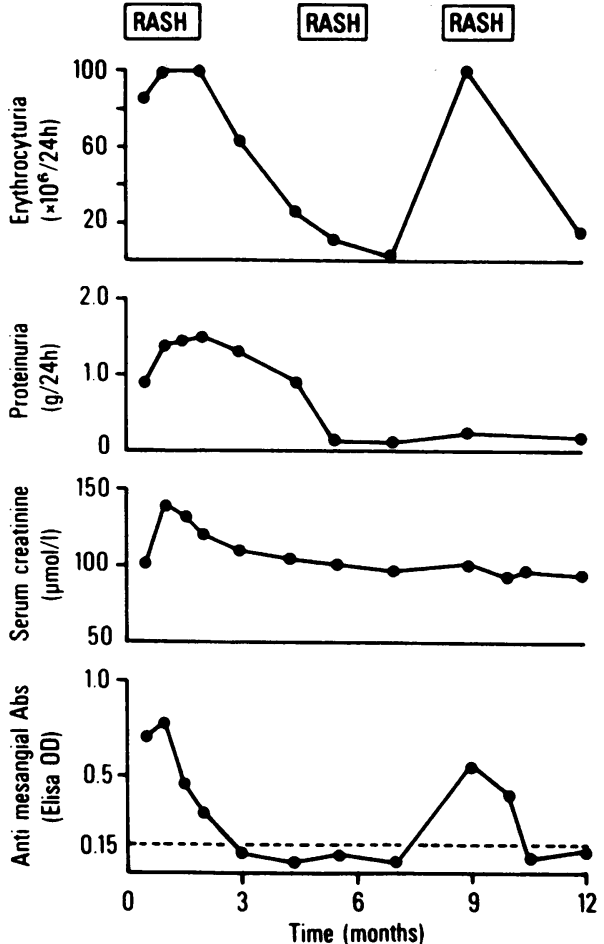
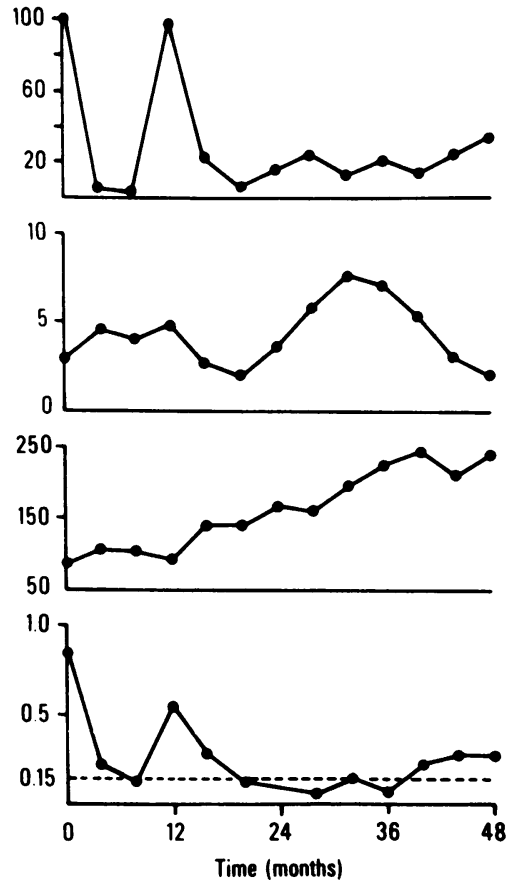

Figure 8. (Left) Anti-mesangial antibodies, serum creatinine, proteinuria, and erythrocyturia during relapse and remission in a patient with HSP: of the three episodes of active HSP with rash, only two were accompanied by active nephritis (HSN; see text) and autoantibody. (Right) Anti-mesangial antibodies, serum creatinine, proteinuria, and erythrocyturia during relapse and remission in a patient with IgA nephropathy during follow-up over $4 \mathrm{yr}$.
The functional effects of IgG-anti-mesangial cell autoantibodies in IgAN in vivo are unknown. Potentially, alteration of mesangial cell function, matrix synthesis may ensue, or they may be nephritogenic, by inducing mesangial injury. Their exclusive detection in IgA-related glomerulopathies suggests a marker of common autoimmune mechanisms leading to their production. In experimental immune complex nephritides, characterized by the accumulation of granular deposits in renal structures, immunoglobulin accretion may not only be the consequence of deposition of circulating immune complexes, but also of antigen-antibody complexes aggregated locally or formed in situ (39). Although not established in disease in humans, these mechanisms are potentially active in vivo in IgArelated nephropathies, since IgG anti-mesangial cell antibodies might also act as planted antigens for serum IgA rheumatoid factor. The simultaneous detection of IgG-MESCA and IgA rheumatoid factor, products of polyclonal B cell activation, only during macroscopic hematuria (40) suggests that both these species contribute to glomerular injury and induction of nephritis by such a mechanism. IgG-MESCA may also serve as a focus for accretion of immune lattices by other mechanisms, for example by promoting glomerular deposition of soluble IgA-IgG aggregates containing the IgG autoantibody. Antimesangial cell antibodies bound directly to the mesangial regions of normal human kidney, supporting this mechanism in vivo. IgA rheumatoid factor has been found in patient sera (41), but we have been unable to demonstrate the presence of IgA rheumatoid factor idiotypes in renal biopsies of patients using a rabbit antisera with specificity for rheumatoid factor idiotype (provided by A. Gharavi, Hospital for Special Surgery, New York; data not presented).

Accumulating evidence supports existence of a complement-mediated component in glomerular injury in $\operatorname{IgA}$ nephropathy (23). IgG is an efficient activator of complement (42) but the interaction between $\operatorname{IgA}$ and the complement sys- tem in vivo remains a matter of controversy (43). Several studies have shown that monomeric IgA does not activate complement (44) and may even inhibit complement activation (45). In contrast, Hiemstra et al. (46) have reported that $\operatorname{Ig} A_{1} F\left(a b^{\prime}\right)_{2}$ fragments can activate the alternative pathway of complement, and alternative pathway activation is induced only by plasticbound but not specific antigen-bound IgA (47); Imai et al. (48) were also unable to detect complement activation by human IgA immune complexes. Animal models of IgAN have demonstrated the absence of urinary abnormalities and the mild or equivocal histological changes induced by IgA deposition alone in contrast to the microscopic hematuria and glomerulonephritis observed when IgG and $\mathrm{C}_{3}$ are co-deposited with IgA immune complexes (24).

Affinity of circulating IgG in the IgA-related nephropathies for mesangial cell components was confirmed by ELISA, Western blotting, and immunofluorescence microscopy. Specific autoantibody binding was demonstrated in the $F\left(a b^{\prime}\right)_{2}$ studies excluding binding via mesangial $\mathrm{Fc}$ receptors (49) or through non-antibody-affinity mechanisms of immune complexes as has been suggested recently shown to explain patient sera IgA binding to type IV collagen (50). Furthermore, conventional plate blocking agents were avoided, by the use of Tween 20 to prevent nonspecific adherence of molecules to the microtiter plates, avoiding problems with fibronectin complexing with IgG and IgA bound to gelatin (50) and the presence of such complexes or anti-albumin antibodies (51), yielding false-positive results. Standardization of our ELISA systems allowed a precise comparison to be made between the whole glomerular and mesangial cell preparations. This revealed a close correlation between the antibody titers detected using ligand from both sources, thereby suggesting the identity of the antigens. The poorer signal-to-background IgG binding demonstrated with the crude glomerular extract was probably secondary to interference with antigen binding to the plastic microtiter 
plates by nonantigenic glomerular components, and resulted in higher sensitivity of the ligand of mesangial cell origin. Identity of the autoantigen present in both ligand preparations was further supported by the Western blotting experiments. These showed reactivity of IgG from ELISA-positive IgAN and HSP sera with antigen carrying moieties of 48 and $55 \mathrm{kD}$ from both extracts. Competitive inhibition studies (data not shown) also demonstrated inhibition of IgG-MESCA activity (> 75\%) by adsorption with ligand from whole glomeruli, and vice versa. FPLC-ELISA profiles, however, revealed at least five distinct molecular mass peaks with antigenic activity with variation in the affinity of serum IgG to mesangial antigenic components between patients. This heterogeneity in components of antigen recognition in the nonreduced ligand suggests that more than one autoantigen is present on mesangial cells, and is of potential immunopathogenic significance in the wide clinicopathological spectrum associated with IgA-related glomerulonephritis $(1,5)$. We are currently further examining the characteristics of these components.

In demonstrating IgG binding to normal human kidney, reactivity with a receptor for the Fc portion of IgG has not been formally excluded in tissue. However, the absence of positive results using control sera strongly argues against such a mechanism. Localization of FITC-conjugated serum IgG, binding to the capillary loops and periphery of the mesangial stalk, confirms previous results (33), and this site, the glomerular region preferentially associated with IgG deposits in renal biopsy studies (26), suggests that the mesangial antigen may be concentrated, or exposed, at these sites in normal renal tissue. The IgG from ELISA-positive serum also bound to a proportion of mesangial cells in culture in a uniform speckled membrane-associated pattern implying that the target antigen is a membrane component or closely associated with the membrane.

The variable presence of the autoantigen, detectable by ELISA, in different mesangial cell preparations suggests modulation of antigen expression at the cell membrane or synthesis of matrix constituents. The failure of antibody to bind to all mesangial cells also suggests this may be dependent upon growth phase or local cellular factors such as adhesion or cytokine production.

These data demonstrate that localization of the only autoantigen identified and present in whole normal glomeruli is expressed in the mesangial cell and show that circulating IgG isotype autoantibodies with affinity for antigen(s) expressed by human mesangial cells are present in the IgA-related nephropathies and HSP. Their detection during activity in both diseases supports a common autoimmune component in glomerular injury. The biochemical characterization and production of monoclonal antibodies against the mesangial antigen will allow further definition of its tissue-specific nature and examination of regulatory factors, providing insight into the nature of autoimmunity in IgA disease.

\section{Acknowledgments}

Dr. O'Donoghue was supported by a North West Regional Training Fellowship. Mrs. Darvill was supported by a National Kidney Research Fund grant.

\section{References}

1. D'Amico, G. 1987. The commonest glomerulonephritis in the world: IgA nephropathy. Q.J. Med. 64:709-727.
2. Berger, J., and N. Hinglais. 1968. Les dépots intracapillaires d'IgA-IgG. $J$. Urol. Néphrol. 74:694-695.

3. Druet, P., J. Bariety, and G. Lagrue. 1970. Les glomerulopathies primitives à depots mesangiaux d'IgA et IgG. Presse Med. 78:583-587.

4. Emancipator, S. N., and M. E. Lamm. 1989. IgA nephropathy: pathogenesis of the most common form of glomerulonephritis. Lab. Invest. 60:168-183.

5. Emancipator, S. N., G. R. Gallo, and M. E. Lamm. 1985. IgA nephropathy perspectives on pathogenesis and classification. Clin. Nephrol. 24:161-179.

6. Nicholls, K. M., K. F. Fairley, J. P. Dowling, and P. Kincaid-Smith. 1984. The clinical course of mesangial IgA associated nephropathy in adults. $Q$. J. Med. 210:227-250.

7. Zimmerman, S. W., and P. M. Burkholder. 1985. Immunoglobulin A nephropathy. Arch. Intern. Med. 135:1217-1223.

8. D’Amico, G., E. Imbasciati, G. Barbiano di Belgioioso, S. Bertoli, G. Fogazzi, F. Ferrario, G. Fellin, A. Ragni, G. Colasanti, L. Minetti, et al. 1985. Idiopathic IgA mesangial nephropathy: clinical and histological study of 374 patients. Medicine (Baltimore) 64:49-60.

9. Border, W. A. 1988. Distinguishing minimal-change disease from mesangial disorders. Kidney Int. 34:419-434.

10. Vilches, A. R., D. R. Turner, J. S. Cameron, C. S. Ogg, C. Chantler, and D. G. Williams. 1982. Significance of mesangial IgM deposition in minimal change nephrotic syndrome. Lab. Invest. 46:10-15.

11. Conley, M. E., M. D. Cooper, and A. F. Michael. 1980. Selective deposition of immunoglobulin A in IgA nephropathy, anaphylactoid purpura nephritis, and systemic lupus erythematosus. J. Clin. Invest. 86:1432-1436.

12. Roth, D. A., D. R. Wilz, and G. B. Theil. 1985. Schönlein-Henoch syndrome in adults. $Q$. J. Med. 55:145-152.

13. Tsai, C. C., J. Giangiacomo, and J. Zucker. 1975. Dermal Iga deposits in Henoch-Schonlein purpura and Berger's nephritis. Lancet. $i: 342-343$.

14. Weiss, J. H., D. B. Bhathena, J. J. Curtis, B. A. Lucas, and R. G. Luke. 1978. A possible relationship between Henoch-Schonlein syndrome and IgA nephropathy. Nephron. 22:588-91.

15. Meadow, S. R., and D. G. Scott. 1985. Berger disease/Henoch-Schönlein syndrome without the rash. J. Pediatr. 27-32.

16. Feehaly, J. 1988. Immune mechanisms in glomerular IgA deposition. Nephrol. Dial. Transplant. 3:361-378.

17. D'Amico, G., L. Minetti, C. Ponticelli, G. Fellin, F. Ferrario, G. Barbiano di Belgioioso, E. Imbasciati, A. Ragni, S. Bertoli, G. Fogazzi, et al. 1986. Prognostic indicators in idiopathic IgA mesangial nephropathy. Q. J. Med. 59:363-378.

18. Pfaffenboch, G., M. E. Lamm, and I. Gigli. 1982. Activation of the guinea pig alternative complement pathway by mouse IgA immune complexes. J. Exp. Med. 155:231-147.

19. Pasternack, A., P. Collin, J. Mustonen, T. Reunala, I. Rantala, K. Laurila and A.-M. Teppo. 1990. Glomerular IgA deposits in patients with celiac disease. Clin. Nephrol. 34:56-60.

20. Kobayashi, Y., S. Tateno, Y. Hiki, and H. Shigematsu. 1983. IgA nephropathy: prognostic significance of proteinuria and histological alterations. Nephron. 34:146-152.

21. Rifai, A., A. Chen, and H. Imai. 1987. Complement activation in experimental IgA nephropathy: an antigen-mediated process. Kidney Int. 32:838-843.

22. Tomino, Y., H. Sakai, M. Endoh, T. Suga, M. Miura, H. Kaneshige, and Y. Nomoto. 1983. Cross-reactivity of IgA antibodies between renal mesangial areas and nuclei of tonsillar cells in patients with IgA nephropathy. Clin. Exp. Immunol. 51:605-610.

23. Rauterberg, E. W., H.-M. Lieberknecht, A.-M. Wingen, and E. Ritz. 1987. Complement membrane attack (MAC) in idiopathic IgA glomerulonephritis. Kidney Int. 31:820-829.

24. Emancipator, S. N., Z. Ovary, and M. E. Lamm. 1987. The role of mesangial complement in the hematuria of experimental IgA nephropathy. Lab. Invest. 57:269-280.

25. Levinsky, R. J., and T. M. Barratt. 1979. IgA immune complexes in Henoch-Schönlein purpura. Lancet. ii:1100-1113.

26. Syre, G. 1983. IgA mesangial glomerulonephritis: significance and pathogenesis of segmental-focal glomerular lesions. Virchows Arch. A(Pathol. Anat.), 420:11-24.

27. Czerkinsky, C., W. J. Koopman, S. Jackson, J. E. Collins, S. S. Crago, R. E. Schroehenloher, B. A. Julian, J. H. Galla, and J. Mestecky. 1986. Circulating immune complexes and immunoglobulin $A$ rheumatoid factor in patients with mesangial immunoglobulin A nephropathies. J. Clin. Invest. 77:1931-1938.

28. Nomoto, Y., T. Suga, M. Miura, H. Nomoto, Y. Tomino, and H. Sakai. 1986. Characterisation of an acidic nuclear protein recognised by autoantibodies in the sera from patients with IgA nephropathy. Clin. Exp. Immunol. 65:513519.

29. Yap, H. K., R. S. Sakai, L. Bahn, V. Rappaport, K. T. Woo, V. Ananthurman, C. H. Lim, G. S. Chiang, and J. C. Jordan. 1988. Antivascular endothelial cell antibodies in patients with IgA nephropathy: frequency and clinical significance. Clin. Immunol. Immunopathol. 49:450-462.

30. Frampton, G., T. Harada, and J. S. Cameron. 1988. IgA autoantibodies in Berger's disease. Nephrol. Dial. Transplant. 3:510. (Abstr.)

31. Cederholm, B., J. Wieslander, P. Bygren, and D. Heinegard. 1986. Pa- 
tients with IgA nephropathy have circulating anti-basement membrane antibodies reacting with structures common to collagen I, II and IV. Proc. Natl. Acad. Sci. USA. 83:6151-6155.

32. Ballardie, F. W., S. Williams, and P. E. C. Brenchley. 1987. IgG antibodies to glomerular antigens in IgA nephropathy: detection and clinical significance. Nephrol. Dial. Transplant. 2:422. (Abstr.)

33. Ballardie, F. W., P. E. Brenchley, S. Williams, and D. J. O'Donoghue. 1988. Autoimmunity in IgA nephropathy. Lancet. ii:587-592.

34. O'Donoghue, D. J., P. E. C. Brenchley, and F. W. Ballardie. 1988. Autoantibodies to glomerular antigens in adult Henoch-Schonlein nephritis. Nephrol. Dial. Transplant. 3:837. (Abstr.)

35. Striker, G. E., and L. J. Striker. 1985. Glomerular cell culture. Lab. Invest. 53:122-131.

36. Striker, G. E., P. D. Killen, and F. M. Farin. 1980. Human glomerular cells in vitro: isolation and characterization. Transplant. Proc. 12:88-100.

37. Parham, P. 1986. Preparation and purification of active fragments of mouse monoclonal antibodies. In Immunochemistry, Volume I. Blackwell Scientific Publications, Ltd., Oxford.

38. Guesdan, J. L., T. Termych, and S. Avrameas. 1979. The use of avidinbiotin interaction in immunoenzymatic techniques. J. Histochem. Cytochem. 27:1131-1140.

39. Brentjens, J. R., and G. Andres. 1989. Interaction of antibodies with renal cell surface antigens. Kidney Int. 35:954-968.

40. Ballardie, F. W., P. E. C. Brenchley, and D. J. O'Donoghue. 1988. Autoantibodies in IgA nephropathy: differential secretion of Ig isotypes during haematuria. Nephrol. Dial. Transplant. 3:524-525.

41. Sinico, R. A., A. Fornasieri, and N. Oreni. 1986. Polymeric IgA rheumatoid factor in idiopathic IgA mesangial nephropathy (Berger's disease). J. Immunol. 137:536-41.
42. Ratnoff, W. D., D. T. Fearon, and K. F. Austen. 1983. The role of antibody in the activation of the alternative complement pathway. Springer Semin. Immunopathol. 6:361-384.

43. Kilian, M., J. Mestecky, and M. W. Russell. 1988. Defense mechanisms involving Fc-dependent functions of immunoglobulin A and their subversion by bacterial immunoglobulin A proteases. Microbiol. Rev. 52:296-318.

44. Colten, H. R., and J. Bienerstock. 1976. Lack of $\mathrm{C}_{3}$ activation through the classical or alternative pathways by human secretory IgA anti-blood group A antibody. Adv. Exp. Med. 45:305-312.

45. Griffiss, J., and D. K. Goroff. 1983. IgA block IgM and IgG-initiated immune lysis by separate molecular mechanisms. J. Immunol. 130:2882-2885.

46. Hiemstra, P. S., J. Biewenga, A. Gorter, M. E. Stuurman, A. Faber, L. A van Es, and M. R. Daha. 1988. Activation of complement by human serum IgA secretory IgA and $\operatorname{IgA}_{1}$ fragments. Mol. Immunol. 25:527-533.

47. Russell, M. W., and B. Mansa. 1989. Complement-fixing properties of human IgA antibodies: alternative pathway complement activation by plastic bound but not specific antigen-bound IgA. Scand. J. Immunol. 30:175-183.

48. Imai, H., A. Chen, R. J. Wyatt, and A. Rifai. 1988. Lack of complement activation by human IgA immune complexes. Clin. Exp. Immunol. 73:479-483.

49. Santiago, A., J. Satriano, S. DeCandido, H. Holthofer, R. Schreiber, J. Unkeless, and D. Schlondorff. 1989. A specific Fc gamma receptor on cultured rat mesangial cells. J. Immunol. 143:2575-2582.

50. Cederholm, B., J. Wieslander, P. Bygren, and D. Heinegard. 1988. Circulating complexes containing IgA and fibronectin in patients with primary IgA nephropathy. Proc. Natl. Acad. Sci. USA. 85:4865-4868.

51. Woodroff, A. J., A. A. Gormley, P. E. McKenzie, A. M. Wootan, A. J. Thompson, A. E. Seymour, and A. R. Clarkson. 1980. Immunologic studies in IgA nephropathy. Kidney Int. 18:366-374. 